\title{
cAMP-dependent inhibition is dominant in regulating superoxide production in the bone-resorbing osteoclasts
}

\author{
C E M Berger ${ }^{1,2}$, B R Horrocks ${ }^{2}$ and H K Datta ${ }^{1}$ \\ ${ }^{1}$ Department of Clinical Biochemistry, The Medical School, Framlington Place, University of Newcastle, Newcastle upon Tyne NE2 4HH, UK \\ and ${ }^{2}$ Chemistry Department, Bedson Building, University of Newcastle, Newcastle Upon Tyne NE1 7RU, UK \\ (Requests for offprints should be addressed to H K Datta)
}

\begin{abstract}
Calciotropic hormones such as parathyroid hormone (PTH) and calcitonin have been shown to have stimulatory and inhibitory effects respectively on superoxide anion $\left(\mathrm{O}_{2}{ }^{-}\right)$generation by osteoclasts, but the exact intracellular signalling mediating these pathways has not been investigated. In order to elucidate the intracellular pathways controlling $\mathrm{O}_{2}{ }^{-}$generation, we have carried out a systematic study of the effect of different agents on $\mathrm{O}_{2}{ }^{-}$production in osteoclasts cultured on bovine cortical bone. Dibutyryl cAMP and cholera toxin, while having no effect on the basal level of $\mathrm{O}_{2}{ }^{-}$production in boneresorbing osteoclasts, were, however, found to completely block the stimulation of free radical production by PTH, pertussis toxin and ionomycin. The stimulation of $\mathrm{O}_{2}{ }^{-}$ production was found to be independent of protein kinase C-dependent pathways since the presence of bisindolyl-
\end{abstract}

maleimide (GF109203X) $(1 \mu \mathrm{M})$ did not block stimulation by $\mathrm{PTH}$ and pertussis toxin. Interestingly, while exposure to bisindolylmaleimide at this concentration did not have any effect on the basal level of $\mathrm{O}_{2}{ }^{-}$production, exposure to a higher concentration $(10 \mu \mathrm{M})$, which is known to inhibit both protein kinase $\mathrm{C}$ and $\mathrm{A}$, produced significant stimulation. These in vitro findings suggest that in the bone-resorbing cells, cAMP-dependent protein kinases prevent further stimulation of NADPH oxidase by agents such as PTH and pertussis toxin. The increase in cAMP has also been recently demonstrated to be associated with down-regulation of the oxidative burst in adherent neutrophils; and the findings reported here suggest a similar role for cAMP in $\mathrm{O}_{2}{ }^{-}$generation in osteoclasts cultured on bone.

Journal of Endocrinology (1998) 158, 311-318

\section{Introduction}

The osteoclast, a multinucleate cell, is unique among the cells of macrophage/monocytic lineage in its ability to carry out extracellular bone dissolution, a process of resorption involving the secretion of hydrolytic enzymes and protons and the generation of superoxide anions $\left(\mathrm{O}_{2}{ }^{-}\right)$. Osteoclastic bone resorption is inhibited by calcitonin which leads to increased levels of cytosolic cAMP and calcium via two different G-proteins (Zaidi et al. 1990). It is generally accepted that the modulation of osteoclast activity by other major hormones, such as parathyroid hormone (PTH), 1,25-dihydroxycholecalciferol and oestrogens is mediated indirectly via cells of osteoblast lineage. However, a number of studies have recently demonstrated that osteoclasts do in fact possess receptors for PTH (Agarwala \& Gay 1992, Tong et al. 1995, May \& Gay 1997), 1,25-dihydroxycholecalciferol (Mee et al. 1996) and oestrogens (Kameda et al. 1997). The exposure of osteoclasts to PTH was found to directly stimulate hydrogen ion production via a G-proteincoupled receptor (May \& Gay 1995, 1997). One possible explanation for the failure of earlier studies to identify direct acute modulatory effects of these major hormones on the osteoclast is their dependence on the in vitro boneresorption assays, which are known to be quite insensitive and imprecise (Boyde \& Jones 1991). Recent studies, employing $\mathrm{O}_{2}{ }^{-}$production by the osteoclast as an index of osteoclast function, have also demonstrated an instantaneous $\mathrm{O}_{2}{ }^{-}$burst in isolated osteoclasts following exposure to PTH (Datta et al. 1996).

Both indirect and direct measurements have shown that osteoclasts produce $\mathrm{O}_{2}{ }^{-}$(Garret et al. 1990), the production of the anion being inhibited by calcitonin and elevated extracellular calcium, and stimulated by bone matrix and PTH (Datta et al. 1995, 1996). The results of these studies suggest that the agents that inhibit and activate osteoclastic bone resorption have corresponding effects on $\mathrm{O}_{2}{ }^{-}$production by these cells, implying a link between $\mathrm{O}_{2}{ }^{-}$production and osteoclast activity. The importance of free radicals in osteoclast function was first suggested on observation of the abolition of cell resorptive activity by superoxide dismutase (Albanese et al. 1991) and nitric oxide (MacIntyre et al. 1991). In view of the important role of $\mathrm{O}_{2}{ }^{-}$in osteoclastic bone resorption, it is vital to understand the precise intracellular signalling that 
is involved in the regulation of free radical production. Like neutrophils and macrophages, osteoclasts also express NADPH oxidase (Steinbeck et al. 1994). $\mathrm{O}_{2}{ }^{-}$produced by leucocytes, including neutrophils and macrophages, plays an important role in the destruction of microorganisms. These cells are known to produce $\mathrm{O}_{2}{ }^{-}$by activating the NADPH oxidase system after exposure to bacteria, which is an essential step in the destruction and phagocytosis of the pathogens. In contrast, $\mathrm{O}_{2}{ }^{-}$produced by osteoclasts has been shown to be up-regulated by components of the extracellular matrix and divalent cations (Datta et al. 1995). The present investigation was designed to elucidate the role of intracellular second messengers in the regulation of $\mathrm{O}_{2}{ }^{-}$production in osteoclasts.

\section{Materials and Methods}

\section{Reagents}

Cytochrome $c$ from horse heart, bovine liver superoxide dismutase, dibutyryl cAMP, pertussis toxin, PTH, fetal calf serum and other organic and inorganic chemicals were obtained from Sigma (Poole, Dorset, UK). Forskolin was from ICN (Thame, Oxfordshire, UK); bisindolylmaleimide (GF109203X) was from Calbiochem-Novabiochem (Nottingham, UK) and 3,3'-dithiobis(sulphosuccinimidylpropionate) (DTSSP) was supplied by Pierce and Warriner (Chester, Cheshire, UK). $\mathrm{NaClO}_{4}$ and $\mathrm{MgCl}_{2}$ were supplied by BDH (Poole, Dorset, UK). Salmon calcitonin was a gift from Dr Tudor Arvinte (Ciba, Horsham, W Sussex, UK). Medium 199 with Hepes was supplied by Gibco Life Technologies (Paisley, Renfrewshire, Scotland, UK).

\section{Osteoclast bone culture}

Devitalized bovine cortical bone slices were used as substrata for osteoclast culture. In brief, the devitalized bone was sliced into circular discs of $13 \pm 1 \mathrm{~mm}$ in diameter and approximately $1 \mathrm{~mm}$ thick. The bone was then cleaned in distilled water by sonication, followed by a final wash with ethanol and distilled water. Newborn Wistar rats (2-3 days old) were killed by cervical dislocation and their long bones removed and freed from any tissues, curetted and desegregated into prewarmed Medium 199 containing $10 \%$ fetal calf serum $\left(37^{\circ} \mathrm{C}\right)$. The cell suspension was then left for $90 \mathrm{~min}$ at $37^{\circ} \mathrm{C}$ in a humidified $5 \% \mathrm{CO}_{2}$ incubator, allowing the osteoclasts to adhere to the bone slices. Cellular debris was removed by washing the preparation vigorously with a prewarmed phosphate buffer $\left(37^{\circ} \mathrm{C}\right)$, comprising $145 \mathrm{mM} \mathrm{NaCl}$, $4.5 \mathrm{mM} \mathrm{KCl}, 5 \mathrm{mM} \mathrm{NaH}{ }_{2} \mathrm{PO}_{4}, 6 \mathrm{mM}$ glucose, $10 \mathrm{mM}$ Hepes and $1 \mathrm{mM} \mathrm{MgCl} 2$ and adjusted to $\mathrm{pH} 7$ with $\mathrm{NaOH}$, leaving the osteoclasts attached to the substratum. Experiments were carried out in wells containing $0.5 \mathrm{ml}$ phosphate buffer and an individual slice of bone to which osteoclasts were attached. For each slice, osteoclasts from one neonatal rat were used.

\section{Osteoblast and osteoclast co-culture}

Our previous studies have shown that ROS17/2.8 produce an undetectable basal level of $\mathrm{O}_{2}{ }^{-}$and no detectable response to PTH (Datta et al. 1996). Therefore, in order to exclude an indirect contribution of osteoblast-like cells to the production of $\mathrm{O}_{2}{ }^{-}$by the bone-resorbing osteoclasts, a series of experiments was performed in which osteoblast-like osteosarcoma cells (ROS17/2.8) were cocultured with osteoclasts. In these experiments osteoclasts were co-cultured with low (5-10\%), intermediate (30$50 \%)$ or high $(>70 \%)$ confluence of ROS17/2.8 cells, and the effect of these cells on basal and PTH-stimulated $\mathrm{O}_{2}{ }^{-}$ generation by the osteoclasts was determined in order to detect the effect on the kinetics and magnitude of the response.

\section{Assessment of the purity of the osteoclast culture}

The contaminating non-osteoclast cells were removed by performing separate experiments in which osteoclast-bone slice cultures were exposed for $3 \mathrm{~min}$ to trypsin/EDTA and then washed vigorously with prewarmed phosphate buffer $\left(37^{\circ} \mathrm{C}\right.$; the composition of the buffer is given above) (Chambers 1978, Sahni et al. 1996). The purity of the osteoclast preparation was checked by microscopy, and the presence of osteoblasts was determined by histochemical staining for alkaline phosphatase (Procedure 85; Sigma). This process was found to produce an osteoclast population of very high purity ( $93 \pm 4 \%$, mean \pm s.E.M.).

\section{Characterization of osteoclasts on bone slices}

In order to characterize the cells after the experiments, bone slices were stained with tartrate-resistant acid phosphatase (TRAP) using an established protocol (kit no. 386; Sigma). Briefly, the cells were fixed on the bone slice in citrate/acetone solution for $30 \mathrm{~s}$ and the slices were then rinsed in deionized water and allowed to air dry for a minimum of $15 \mathrm{~min}$. The slices were then incubated in an acetate/tartrate solution for $1 \mathrm{~h}$ at $37^{\circ} \mathrm{C}$ in the dark, washed for $3 \mathrm{~min}$ in deionized water and stained in acid/haematoxylin solution for $5 \mathrm{~min}$. The number and density of the osteoclasts on well-rinsed and dried slices was ascertained using a Nikon TMS microscope $(\times 400$ magnification).

\section{Measurement of $\mathrm{O}_{2}{ }^{-}$production}

Fabrication of the gold electrode A gold wire $(5 \mathrm{~mm}$ in length and $1 \mathrm{~mm}$ in diameter) was soldered to a copper wire before insertion of the whole into a capillary glass 
tube $2 \mathrm{~mm}$ in diameter. The gold was placed near one end of the capillary tube (Goodfellow, Cambridge, UK). The wire, including the solder joint, was then potted in an epoxy resin (Araldite) and allowed to dry for $12 \mathrm{~h}$. The cross-section of the gold wire was exposed by grinding the electrode on a polishing wheel. The gold surface was then polished with successively finer grades of diamond paste and/or alumina.

Immobilization of cytochrome $c$ at a surfacemodified gold electrode The electrode was made as previously described (McNeil et al. 1989). Briefly, it was cleaned by leaving it for $1 \mathrm{~min}$ at $+1 \mathrm{~V}$ and $1 \mathrm{~min}$ at $-1 \mathrm{~V}$ against an $\mathrm{Ag} / \mathrm{AgCl}$ electrode in a $0 \cdot 1 \mathrm{M} \mathrm{HCl}$ solution. After being rinsed with distilled water, the electrode was immersed in a fresh aqueous solution of $50 \mathrm{mM}$ DTSSP for $1 \mathrm{~min}$ and immediately afterwards in $125 \mu \mathrm{l} 2 \mathrm{mM}$ cytochrome $c$ solution prepared in $100 \mathrm{mM}$ phosphate buffer containing $20 \mathrm{mM} \mathrm{NaClO}_{4}$ and incubated at $4{ }^{\circ} \mathrm{C}$ for about $20 \mathrm{~h}$. The electrodes were found to be stable for up to $6 \mathrm{~h}$.

Calibration of the electrode $\mathrm{O}_{2}{ }^{-}$was generated as an intermediate during the oxidation of xanthine by xanthine oxidase (XOD) in $20 \mathrm{mM} \mathrm{NaH} \mathrm{PO}_{4}$ buffer ( $\mathrm{pH} 7 \cdot 4$ ) containing $\mathrm{NaCl}(150 \mathrm{mM})$ and $\mathrm{NaClO}_{4}(100 \mathrm{mM})$ at room temperature. A stock solution of xanthine $(30 \mathrm{mM})$ in $\mathrm{KOH}(0 \cdot 1 \mathrm{M})$ was prepared and added to the electrochemical cell containing the phosphate buffer to produce a final concentration of $3 \mathrm{mM}$. XOD was added to give a final concentration of $0.8 \mu \mathrm{M}$, and the rate of current production at $+100 \mathrm{mV}$ vs $\mathrm{Ag} / \mathrm{AgCl}$ during the reoxidation of reduced cytochrome $c$ was measured using a low-current potentiostat.

Instrumentation The electrochemical instrumentation consisted of a locally constructed high-sensitivity potentiostat (Electronics Workshop, Department of Chemistry, University of Newcastle upon Tyne) interfaced to a 486DX $25 \mathrm{MHz}$ PC via an analogue interface board (DAS1602; Keithley Metrabyte, Reading, Berks, UK). The software was written in MS Visual Basic and was used to control the potentiostat, emulate a $Y-t$ chart recorder and transfer the current-time data to a spreadsheet for graphing and analysis.

The currents measured at millimetre sized superoxide electrodes in our experiments were of the order of $1-100$ $\mathrm{pA}$ and therefore an earthed aluminium box was used as a Faraday cage to contain the experiment culture well and the electrodes were connected to the potentiostat via guarded inputs. The largest available feedback resistors, i.e. $0 \cdot 1-100 \mathrm{G} \Omega$, were used to maximize the signal-to-noise ratio. An isolated power supply and software-enabled RC filter with time constant of $1 \mathrm{~s}$ were also used. The analogue output of the potentiostat was digitized at about $250 \mathrm{~Hz}$, and values of current were averaged over intervals

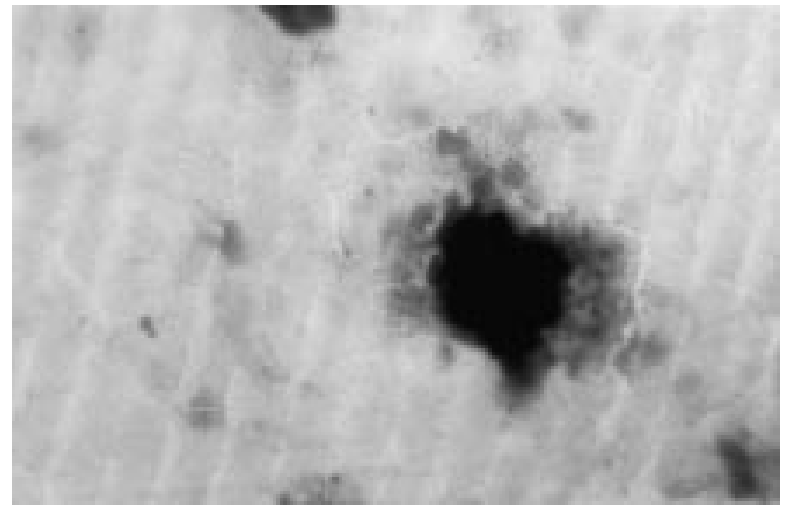

Figure 1 Typical multinucleate TRAP-positive osteoclasts cultured on bone slices for the investigations (magnification $\times 200$ ).

of $0.5 \mathrm{~s}$ or greater and plotted against time on the PC screen.

The position of the electrode could be controlled either manually or by using two-stepper motor-driven translation stages with micron resolution (MFN08-PP; Newport, Newbury, Berks, UK) mounted in an X-Z configuration. The motors were interfaced to the PC via a driver card (Motor Technology; Stockport, UK) and a programmable stepper motor-controller interface (MSTEP-5; Keithley Metrabyte).

\section{Results}

The purity and morphology of the osteoclast culture on the bone slices was determined by TRAP staining, and a typical multinucleate TRAP-positive cell cultured on a bone slice is shown in Fig. 1 (magnification $\times 400$ ). The staining revealed that over $90 \%$ of the cells were TRAPpositive multinucleate cells. The co-culture of osteoclasts with different confluent levels of osteoblast-like cells (ROS17/2.8) was found to have no effect on the kinetics or the magnitude of $\mathrm{O}_{2}{ }^{-}$generation stimulated by PTH.

The specificity of the modified cytochrome $c$ gold electrode to $\mathrm{O}_{2}{ }^{-}$is illustrated by its response to in situ generation of $\mathrm{O}_{2}{ }^{-}$using xanthine/XOD (Fig. 2a). An immediate increase in current is seen when XOD is added to the solution, and addition of superoxide dismutase to the incubating solution produced an immediate fall in the current related to the decrease in the production of $\mathrm{O}_{2}{ }^{-}$ (Fig. 2b). In the experiments, the electrode was positioned between 0.5 and $1 \mathrm{~mm}$ above the slice of bone on to which osteoclasts were fixed.

The acute response of osteoclasts cultured on devitalized cortical bone to PTH $(100 \mathrm{nM})$ and pertussis toxin $(1 \mathrm{ng} / \mathrm{ml})$ is shown in Fig. $3 a$ and $b$ respectively. The two agents showed similar response time, peak height and decay of the response. Osteoclast response to ionomycin $(10 \mu \mathrm{M})$ was also stimulatory, but the kinetics of the $\mathrm{O}_{2}{ }^{-}$ 

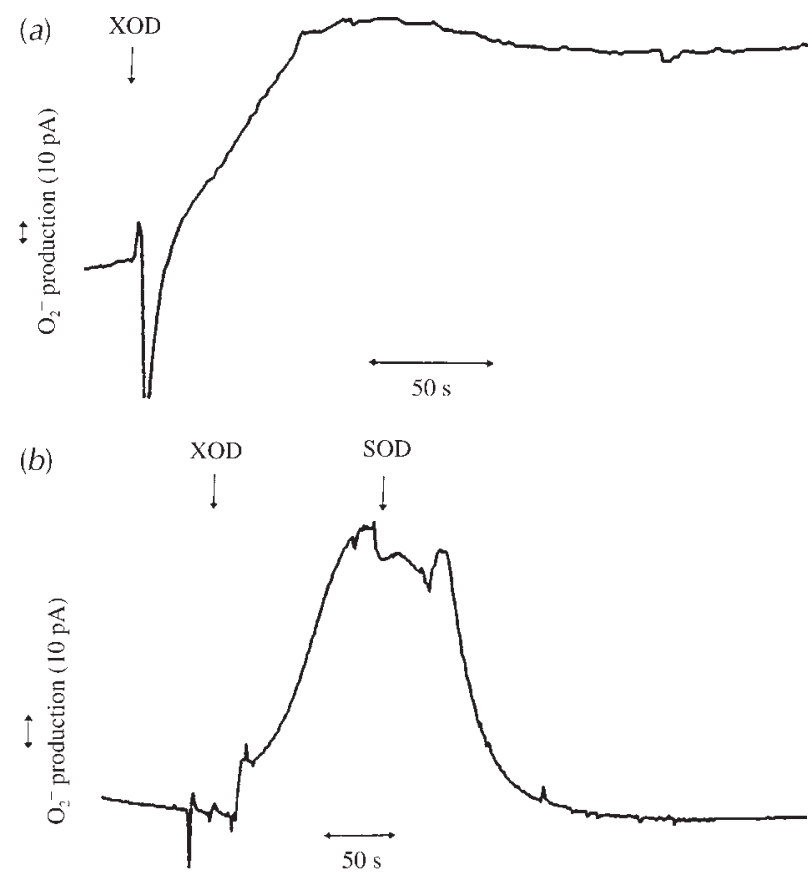

Figure 2 A typical instantaneous response of cytochrome $c$ electrode to in situ generation of $\mathrm{O}_{2}{ }^{-}$using xanthine/XOD (a). The addition of superoxide dismutase (SOD) shows that the electrode current is solely from $\mathrm{O}_{2}{ }^{-}$generation $(b)$.
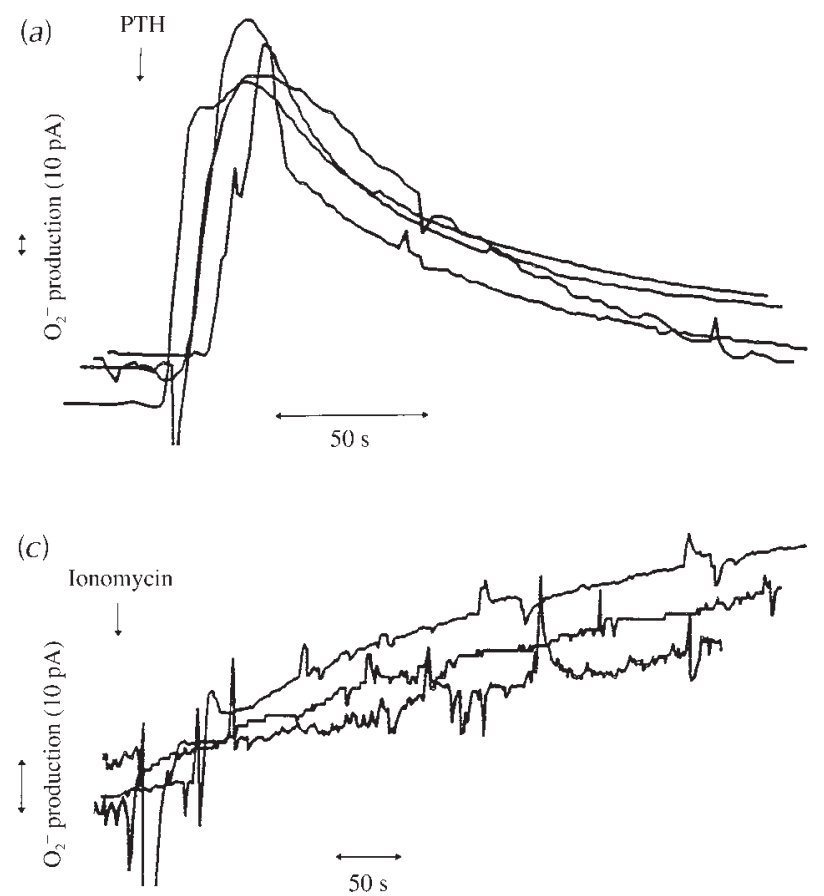

response were quite different from those obtained with PTH or pertussis; a sustained stimulation by the ionophore was evident (Fig. 3c). Although the increase in $\mathrm{O}_{2}{ }^{-}$ production by PTH and pertussis toxin produced was transient, the final level of production of the free radical remained higher than the initial basal levels. That this increase in current was solely due to $\mathrm{O}_{2}{ }^{-}$production was confirmed by exposing the osteoclast culture to superoxide dismutase, which immediately abolished the observed rise in current (Fig. 3d). In fact, exposure to the enzyme was associated with a decrease in the current to below that of the starting level, confirming that osteoclasts cultured on bone produce a constant but sustained basal level of $\mathrm{O}_{2}{ }^{-}$.

We then tested dibutyryl cAMP $(200 \mu \mathrm{M})$, cholera toxin $(5 \mu \mathrm{g} / \mathrm{l})$ and bisindolylmaleimide $(1 \mu \mathrm{M})$ on the osteoclast culture but found that none of these agents had any effect on the basal level of $\mathrm{O}_{2}{ }^{-}$production (Fig. 4a, $b$ and $c$ ). Interestingly, exposure to a higher concentration of bisindolylmaleimide $(10 \mu \mathrm{M}$, Fig. $4 d)$ produced a sustained increase in free radical production with a similar type of response curve to that seen with ionomycin (Fig. 3c).

The action of all the stimulatory agents, i.e. PTH, pertussis toxin and ionomycin, was blocked when the cells were exposed to dibutyryl cAMP $(200 \mu \mathrm{M})$ (Fig. $5 a, b$ and c). Cholera toxin, like dibutyryl cAMP, had no effect on

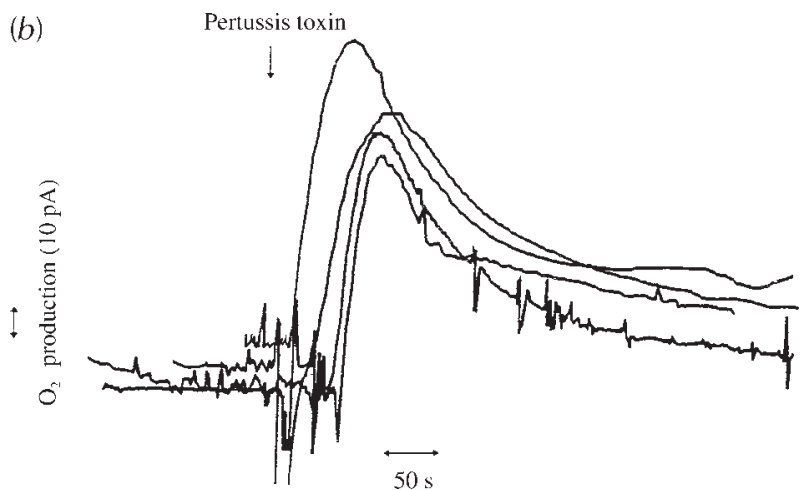

(d)

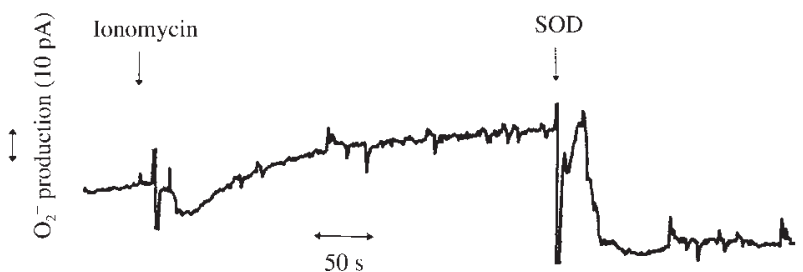

Figure 3 The effect of PTH (100 nM), pertussis toxin $(1 \mathrm{ng} / \mathrm{ml})$ and ionomycin $(10 \mu \mathrm{M})$ on $\mathrm{O}_{2}{ }^{-}$generation by rat osteoclasts cultured on devitalized bovine cortical bone. The agents were added to the culture after baseline production of the radical was established. Similar responses are observed with PTH and pertussis toxin ( $a$ and $b$ ), but ionomycin was found to have a more sustained effect (c). The addition of superoxide dismutase (SOD) shows an instantaneous decline in the rate of $\mathrm{O}_{2}{ }^{-}$production (d). Each profile represents an individual experiment carried out on a separate bone slice, and, in each case, at least four to six replicate experiments were carried out; however, for the sake of clarity not all profiles are displayed. 

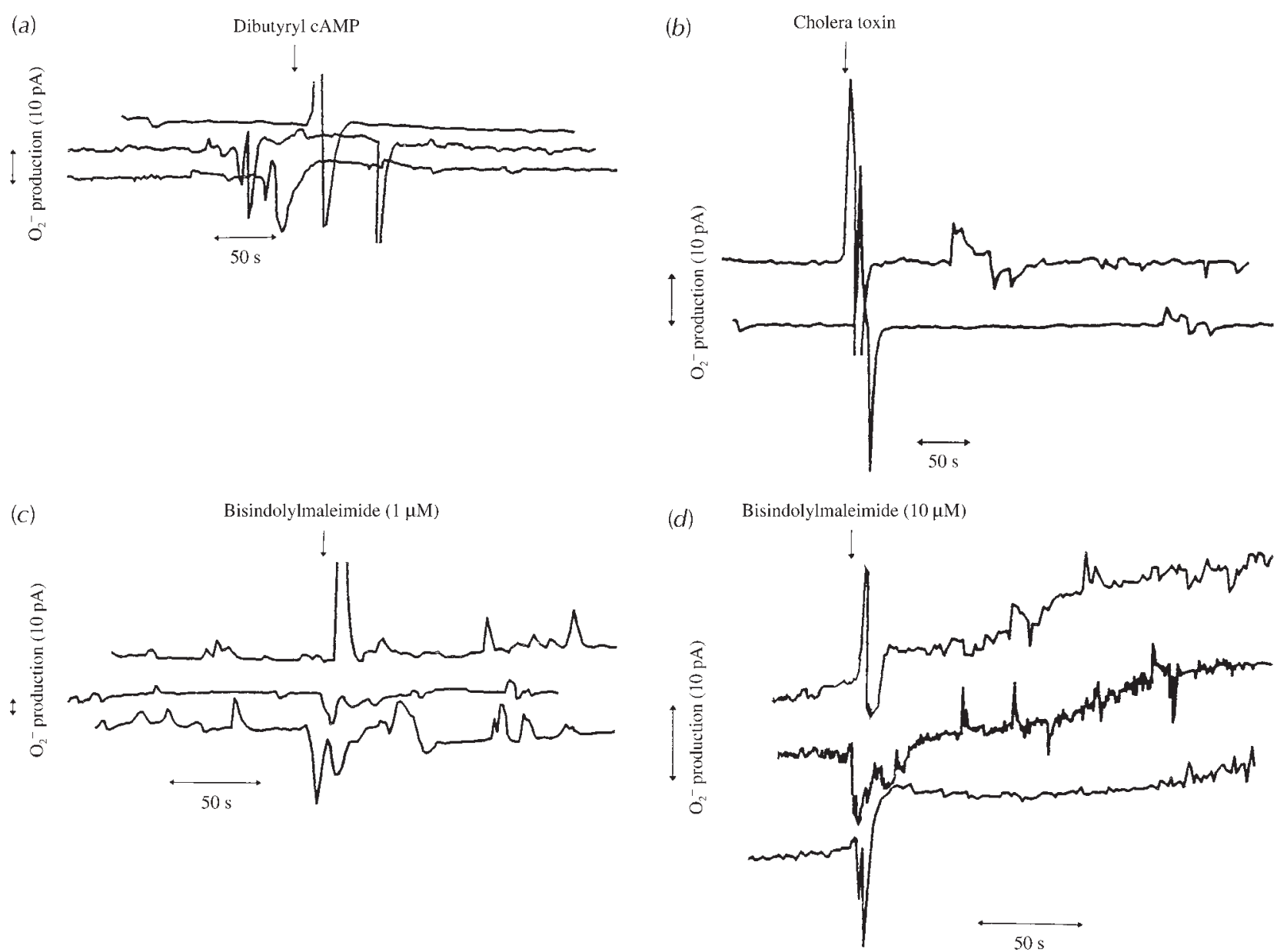

Figure 4 The effect of dibutyryl cAMP $(200 \mu \mathrm{M})$, cholera toxin $(5 \mu \mathrm{g} / \mathrm{l})$ and bisindolylmaleimide $(1$ and $10 \mu \mathrm{M})$ on $\mathrm{O}_{2}{ }^{-}$generation. Three reprentative examples of each different experiment are shown. As can be seen there was no effect on the rate of free radical production with dibutyryl cAMP (a), cholera toxin $(b)$ or bisindolylmaleimide $(1 \mu \mathrm{M})(c)$. At a concentration of $10 \mu \mathrm{M}$, bisindolylmaleimide produced a sustained increase in $\mathrm{O}_{2}{ }^{-}$production $(d)$.

the basal level of the free radical production, but unlike dibutyryl cAMP, the toxin failed to block the stimulation by PTH (Fig. $5 d$ ). However, cholera toxin treatment of the osteoclast culture was found to markedly decrease the extent of stimulation by PTH.

In order to assess the importance of protein kinase $\mathrm{C}$ in mediating the PTH-induced burst of oxygen free radicals, we exposed the cultured osteoclasts to bisindolylmaleimide $(1 \mu \mathrm{M})$ before the addition of PTH (Fig. 6a) (Toullec et al. 1991). Bisindolylmaleimide, a protein kinase C inhibitor, failed to block the stimulation of $\mathrm{O}_{2}{ }^{-}$production by both PTH $(100 \mathrm{nM})$ and pertussis toxin $(1 \mu \mathrm{g} / \mathrm{l})$ when used at $1 \mu \mathrm{M}$ (Fig. $6 a$ and $b$ ). Interestingly, exposure of the cells to bisindolylmaleimide at a concentration known to inhibit both protein kinase $\mathrm{C}$ and $\mathrm{A}(10 \mu \mathrm{M})$ resulted in the prolonged stimulation of radical production (Fig. 4d).

We then ascertained the sensitivity of $\mathrm{O}_{2}{ }^{-}$production by exposing the cells to salmon calcitonin $(10 \mathrm{nM})$, which was found to suppress the anion production (data not shown); similar inhibition was also observed with forskolin $(10 \mu \mathrm{M})$ (Fig. 7).

\section{Discussion}

We found that the kinetics and quantitative aspects of $\mathrm{O}_{2}{ }^{-}$production in osteoclasts cultured on bone matrix and stimulated with PTH were identical in purified osteoclast $(>90 \%$ osteoclast cells as indicated by TRAP staining) and osteoclast-osteoblast co-culture (Datta et al. 1996). Determination of $\mathrm{O}_{2}{ }^{-}$production in the osteoclasts alone and osteoclast and osteoclast-ROS17/2.8 co-culture has shown that the kinetics and magnitude of the stimulation of free radical generation by PTH is unaffected by the presence of osteoblast-like cells (Datta et al. 1996).

Our investigations were carried out on osteoclasts cultured on bone matrix, since our previous studies have 

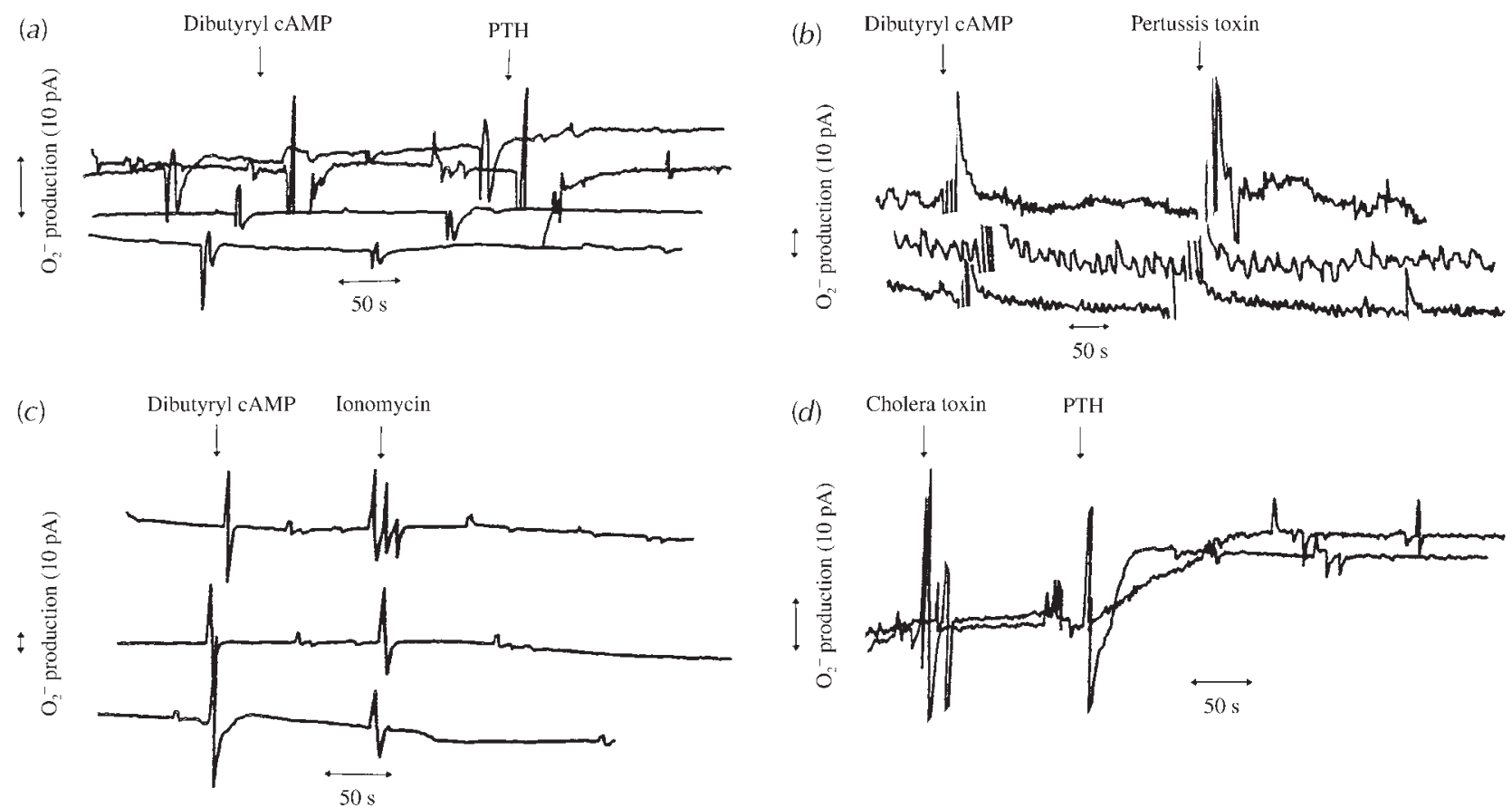

Figure 5 The experiments show the complete blockage of the stimulatory effects of PTH (100 nM) (a), pertussis toxin (1 ng/ml) $(b)$ and ionomycin $(10 \mu \mathrm{M})(\mathrm{c})$, by prior administration of dibutyryl cAMP $(200 \mu \mathrm{M})$. Treatment with cholera toxin $(5 \mu \mathrm{g} / \mathrm{l})$ failed to block the stimulatory effect of PTH $(d)$.

shown that $\mathrm{O}_{2}{ }^{-}$production in osteoclasts cultured in this way is far greater than in cells cultured on plastic (Datta et al. 1995), an effect probably mediated via integrin. We also report that this can be further increased not only by the addition of PTH as reported earlier (Datta et al. 1996), but also by pertussis toxin and ionomycin. Exposure to dibutyryl cAMP and cholera toxin showed that these agents were neither stimulatory nor inhibitory. However, pretreatment with dibutyryl cAMP completely abolished the stimulatory effects of PTH, pertussis toxin and ionomycin. The stimulation by ionomycin and other agents such as PTH and pertussis toxin was not altered by the presence of the protein kinase $\mathrm{C}$ inhibitor bisindolylmaleimide.

The stimulation of free radical production by $\mathrm{PTH}$, pertussis toxin and ionomycin was inhibited in the presence of dibutyryl cAMP. These in vitro results suggest that the inhibitory effects of cAMP-dependent kinase are dominant over the stimulatory signalling in modulating NADPH oxidase in osteoclasts cultured on bone. Whilst stimulation of free radical production is blocked by cAMPdependent pathways, extracellular matrix-mediated free radical production is not affected, suggesting that the up-regulation seen in the osteoclasts cultured on bone rather than plastic is likely to be mediated via integrins and is independent of modulation by cAMP. The importance of cAMP-dependent kinase is further underlined by the fact that, while $1 \mu \mathrm{M}$ bisindolylmaleimide had no effect, higher levels of the agent $(10 \mu \mathrm{M})$ stimulated a free radical burst. In view of the fact that bisindolylmaleimide at $1 \mu \mathrm{M}$ is known to be a potent selective inhibitor of protein kinase $\mathrm{C}$, and at higher concentrations also inhibits protein kinase $\mathrm{A}$, this underlines the dominant inhibitory role of protein kinase $\mathrm{A}$, and hence the inhibition of protein kinase A leads to stimulation of $\mathrm{O}_{2}{ }^{-}$production.

The mechanism of PTH-mediated stimulation is clearly independent of protein kinase $\mathrm{C}$. The fact that pertussis toxin, which catalyses ADP-ribosylation of $G_{i}$, mimics the effect of PTH suggests that the pathway mediating the stimulatory effect of the hormone may involve receptorcoupled inhibition of adenylate cyclase. This contention is further supported by the fact that inhibition by both stimulants is completely blocked by dibutyryl cAMP. However, cholera toxin did not mimic this action of dibutyryl cAMP. One possible explanation for this observation is that ADP-ribosylation of $G_{s} \alpha$ by cholera toxin may not produce sufficiently vigorous stimulation of adenylate cyclase, and therefore produces only a relatively small rise in cytosolic cAMP.

Whilst dibutyryl cAMP and cholera toxin had no effect on the basal production of the free radical, both salmon calcitonin $(10 \mathrm{nM})$ and forskolin $(10 \mu \mathrm{M})$ were found to decrease $\mathrm{O}_{2}{ }^{-}$production. These data suggest that the common inhibitory actions of the latter two agents are cAMP-independent and are probably mediated by the modulation of cation channels. Indeed, recent studies have 

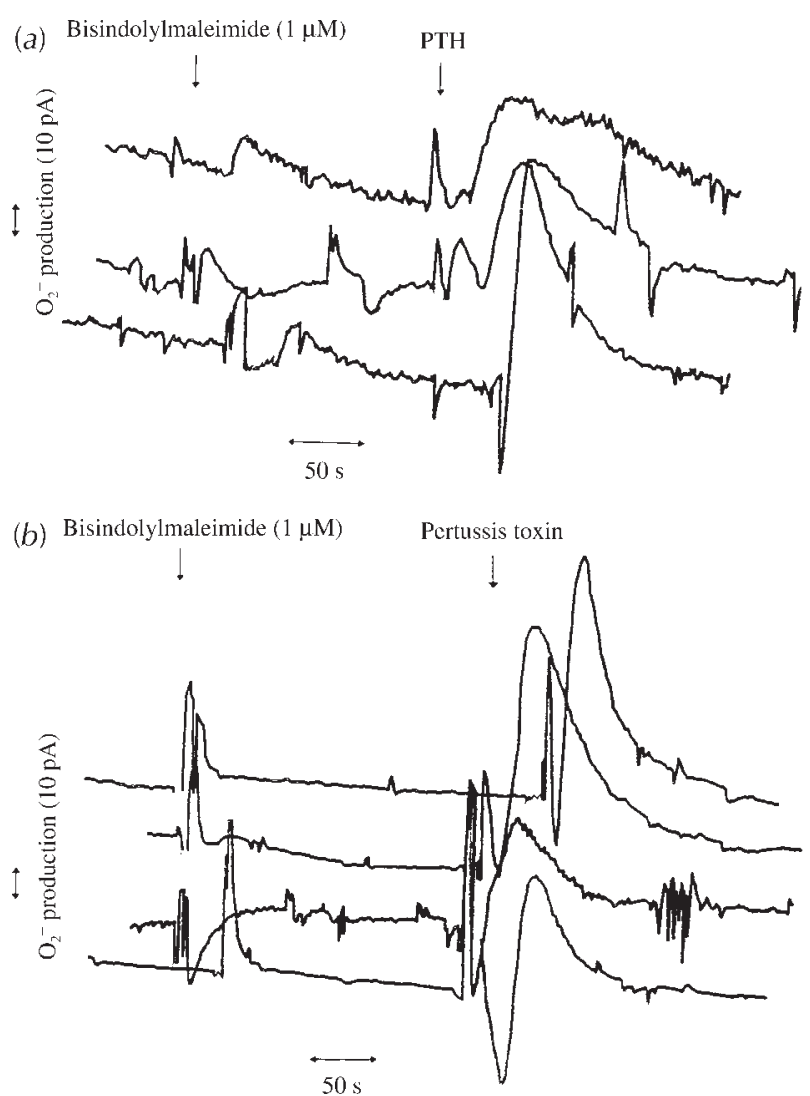

Figure 6 The protein kinase $C$ inhibitor bisindolylmaleimide (GF109203X) (1 $\mu \mathrm{M})$ did not have any effect on PTH- (a) and pertussis toxin- $(b)$ mediated stimulation of $\mathrm{O}_{2}{ }^{-}$generation. For the sake of clarity only three vs four out of six individual profiles are shown.

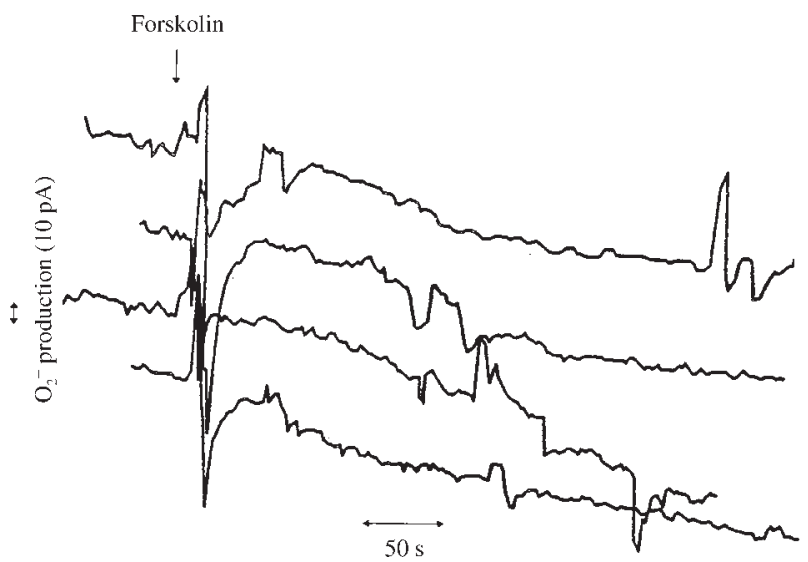

Figure 7 Forskolin $(10 \mu \mathrm{M})$ was found to suppress the baseline levels of $\mathrm{O}_{2}{ }^{-}$generation by osteoclasts.

shown a cAMP-independent direct effect of forskolin on voltage-dependent sodium channels (Ono et al. 1995).

Studies on neutrophils have implied a possible link between $\mathrm{O}_{2}{ }^{-}$production and the stabilization of the membrane potential, with the displacement of charge due to the release of $\mathrm{O}_{2}{ }^{-}$being balanced by $\mathrm{H}^{+}$(derived from the oxidation of NADPH) translocated across the membrane (Henderson et al. 1987, 1988). However, this link is unlikely to be important, since, in osteoclasts, proton pump activation by $\mathrm{PTH}$ is via protein kinase $\mathrm{C}$ (May \& Gay 1997), while $\mathrm{PTH}$-induced $\mathrm{O}_{2}{ }^{-}$production has been shown to be mediated independently of the kinase.

Our observation demonstrating a dominant inhibitory role of cAMP-elevating agents on $\mathrm{O}_{2}{ }^{-}$burst in the osteoclasts seems to suggest the existence of similar intracellular regulatory pathways controlling $\mathrm{O}_{2}{ }^{-}$generation in the cells of macrophage/monocytic lineage, since intracellular cAMP has been shown to be associated with the down-regulation of the oxidative burst in adherent neutrophils (Ottonello et al. 1995). However, further studies are needed to identify the possibility of subtle differences in the intracellular pathways occurring within the cells of macrophage/monocytic lineage and osteoclast and osteoclast-like multinucleate cells.

\section{Acknowledgements}

We are grateful to Action Research for their support.

\section{References}

Agarwala N \& Gay CV 1992 Specific binding of parathyroid hormone to living osteoclasts. Journal of Bone and Mineral Research 7 531-539.

Albanese CV, Salvemini D, Datta HK, Rathod H \& MacIntyre I 1991 Image processing as a probe for the action of NO and oxygen-derived free radicals in isolated cells. Biology of Nitric Oxide, Second International Meeting, London 81a (Abstract).

Boyde A \& Jones S 1991 Pitfalls in the pit measurements [editorial]. Calcified Tissue International 49 65-70.

Chambers TJ 1978 Phagocytosis and trypsin-resistant glass adhesion by osteoclasts in culture. Journal of Pathology 127 55-60.

Datta HK, Manning P, Rathod H \& McNeil CJ 1995 Effect of calcitonin, elevated calcium and extracellular matrices on superoxide anion production by rat osteoclasts. Experimental Physiology $\mathbf{8 0}$ 713-719.

Datta HK, Rathod H, Manning P, Turnbull Y \& McNeil CJ 1996 Parathyroid hormone induces superoxide anion burst in the osteoclast: evidence for the direct instantaneous activation of the osteoclast by the hormone. Journal of Endocrinology 149 269-275.

Garret IR, Boyce BF, Oretto RO, Bonewald L, Poser J \& Mundy GR 1990 Oxygen derived free radicals stimulate osteoclastic bone resorption in rodent bone in vitro and in vivo. Journal of Clinical Investigation 85 632-639.

Henderson LM, Chappell JB \& Jones OTW 1987 The superoxidegenerating NADPH oxidase of human neutrophils is electrogenic and associated with an $\mathrm{H}^{+}$channel. Biochemistry Journal 246 325-329.

Henderson LM, Chappell JB \& Jones OTW 1988 Internal pH changes associated with the activity of NADPH oxidase of human neutrophils. Biochemistry Journal 251 563-567.

Kameda T, Mano H, Yuasa T, Mori Y, Miyazawa K, Shiokawa M, Nakamaru Y, Hiroi E, Hiura K, Kameda A, Yang NN, Hakeda Y \& Kumegawa M 1997 Estrogen inhibits bone resorption by directly inducing apoptosis of the bone-resorbing osteoclast. Journal of Experimental Medicine 186 489-495. 
MacIntyre I, Zaidi M, Alam AST, Datta HK, Moonga BS, Lidbury P, Hecker M \& Vane JR 1991 Osteoclast inhibition: an action of nitric oxide not mediated by cyclic GMP. Proceedings of the National Academy of Sciences of the USA 88 2936-2940.

McNeil CJ, Smith KA, Bellavite P \& Bannister JV 1989 Application of the electrochemistry of cytochrome $c$ to the measurement of superoxide radical production. Free Radical Research Communication 7 89-96.

May LG \& Gay CV 1995 Involvement of protein kinase C in parathyroid stimulation of acid production in osteoclasts. Journal of Bone and Mineral Research 10 S276 (Abstract).

May LG \& Gay CV 1997 Multiple G-protein involvement in parathyroid hormone regulation of acid production by osteoclasts. Journal of Cellular Biochemistry 64 161-170.

Mee AP, Hoyland JA, Braidman IP, Freemont AJ, Davies M \& Mawer EB 1996 Demonstration of vitamin D receptor transcripts in actively resorbing osteoclasts in bone sections. Bone 18 295-299.

Ono K, Fozzard HA \& Hanck DA 1995 A direct effect of forskolin on sodium channel bursting. European Journal of Physiology 429 $561-569$.

Ottonello L, Morone MP, Dapino P \& Dallegri F 1995 cAMP-elevating agents down-regulate the oxidative burst induced by granulocyte-macrophage colony stimulating factor (GM-CSF) in adherent neutrophils. Clinical Experimental Immunology 101 502-506.
Sahni M, Zhou X, Bakiri L, Schlessinger J, Baron R \& Levy JB 1996 Identification of a novel $135-\mathrm{kDa}$ Grb2-binding protein in osteoclasts. Journal of Biological Chemistry 271 33141-33147.

Steinbeck MJ, Appel WH, Verhoeven AJ \& Karnovsky MJ 1994 NADPH-Oxidase expression and in situ production of superoxide by osteoclasts actively resorbing bone. Journal of Cellular Biology 126 765-772.

Tong HS, Lin H, Wang H, Sakai D \& Minkin C 1995 Osteoclasts respond to parathyroid hormone and express mRNA receptor. Journal of Bone and Mineral Research 10 S278 (Abstract).

Toullec D, Pianetti P, Coste H, Bellevergue P, Grand-Perret T, Ajakane M, Baudet V, Boissin P, Boursier E, Loriolle F, Duhamel L, Charon D \& Kirilovsky J 1991 The bisindolylmaleimide GF109203X is a potent and selective inhibitor of proteinase kinase C. Journal of Biological Chemistry 266 15771-15781.

Zaidi M, Datta HK, Moonga BS \& MacIntyre I 1990 Evidence that the action of calcitonin on rat osteoclasts is mediated by two G proteins acting via separate post-receptor pathways. Journal of Endocrinology 126 473-481.

Received 15 August 1997

Revised manuscript received 25 November 1997

Final version received 27 March 1998

Accepted 16 April 1998 